\title{
The need for a chlamydial culture service*
}

\author{
J. R. WILLCOX, P. G. FISK, J. BARROW, AND D. BARLOW \\ From the Chlamydia Research Laboratory, Rayne Institute, and the Department of Genitourinary \\ Medicine, St Thomas's Hospital, London
}

SUMMARY In a prospective study of unselected, female patients attending a sexually transmitted disease clinic one in eight patients would have been erroneously declared free of infection in the absence of a chlamydial culture service. Chlamydia trachomatis is now accepted as a causative organism of non-specific urethritis and post-gonococcal urethritis in men and non-specific genital infection in women. Thus, facilities for the isolation of $C$. trachomatis should be an essential aid in the management of women attending STD clinics. Male patients would also benefit if such facilities were readily available.

\section{Introduction}

Chlamydia trachomatis has become recognised increasingly as a common human pathogen in many disciplines of medicine. The identification of women harbouring $C$. trachomatis is desirable for many reasons. It is now accepted that these women are a potential source of infection to their male partner(s) and that they may develop salpingitis (Mårdh et al., 1977).

In pregnancy there may be premature labour and, after delivery, an increased risk of post-partum pelvic infection in the mother and inclusion conjunctivitis in the child (Rees et al., 1977). Cases of neonatal pneumonitis have also been reported (Beem and Saxon, 1977).

It is regrettable therefore that those few clinics with laboratory facilities for the isolation of $C$. trachomatis tend to be looked on as research centres and are not generally regarded as providing an essential aid to the diagnosis and management of the most common sexually transmitted disease (Department of Health and Social Security, 1976).

In March 1976 a prospective study of female patients attending this department was carried out. Patients were unselected apart from the exclusion of those who had received antibiotic treatment in the previous two months.

*Adapted from a paper presented at the spring meeting of the Medical Society for the Study of Venereal Diseases at Leeds, 19-20 May 1978

Address for reprints: Dr J. Barrow, Lydia Department of Genitourinary Medicine, St Thomas's Hospital, London SE1 7EH

Received for publication 26 October 1978

$D^{*}$
The main aim of the study was to collect data from patients harbouring $C$. trachomatis for comparison with those patients with other sexually transmitted diseases and those who were free from infection.

Over an 18-month period, information was obtained by means of confidential questionnaires, from which-together with clinical and laboratory findings-we hoped to gain a greater understanding of the epidemiology of chlamydial genital infection.

The data presented in this paper are restricted to symptoms and reasons for attendance in unselected female patients.

\section{Patients and methods}

All patients in the study were screened for other sexually transmitted diseases using standard methods (Barlow et al., 1976). Samples were taken from the vagina for microscopy and culture of Trichomonas vaginalis and Candida albicans and from the urethra, cervix, and rectum (where indicated) for microscopy and culture of Neisseria gonorrhoeae. Samples for herpes simplex isolation were taken where clinically indicated. A specimen for cervical cytology and blood for antitreponemal antibodies were also collected.

Specimens for the isolation of C. trachomatis were taken from the endocervix (including junctional material) using sterile cottonwool swabs. The specimens were inoculated on to McCoy cell monolayers either immediately or after storage at $4^{\circ} \mathrm{C}$ overnight. If a longer period was to elapse before inoculation, the samples were kept at $-70^{\circ} \mathrm{C}$. After the slides had been incubated for $\mathbf{4 8}$ hours, $C$. trachomatis was diagnosed by the finding of characteristic brown-staining inclusions after 
flooding of the fixed cell-layers with iodine. Full details of this technique are described elsewhere (Reeve et al., 1975).

\section{Results and discussion}

\section{CHLAMYDIAL SERVICE FOR WOMEN}

During the study over 2000 samples from the female endocervix were processed, and the isolation rate for chlamydiae varied month by month between 20 and $25 \%$ (average $23.6 \%$ ) after exclusion of contaminated specimens.

The symptoms on attendance in three groups of patients are shown in Table 1. Those patients with chlamydial infection alone and those with no sexually transmitted disease (NVD) are compared with patients with gonorrhoea alone (Barlow and Phillips, 1978). There was no significant difference between the presenting symptoms in any of these groups.

The overall isolation rate of $C$. trachomatis in unselected women in our study was similar to that obtained in other studies (Hilton et al., 1974; Oriel et al., 1974; Nayyar et al., 1976; Woolfit and Watt, 1977). Presenting symptoms gave no clue to the presence or absence of chlamydiae, which confirms previous reports (Oriel et al., 1974; Burns et al., 1975; Oriel et al., 1978).

One hundred and seventy-eight $(31 \cdot 4 \%)$ chlamydiae-positive patients were contacts of patients with non-specific urethritis (NSU) (Table 2). At many centres these contacts would have received treatment epidemiologically in the absence of a chlamydial service laboratory.

Table 1 Symptoms on attendance in female patients

\begin{tabular}{|c|c|c|c|c|c|c|}
\hline \multirow[b]{2}{*}{ Symptoms } & \multicolumn{2}{|c|}{$\begin{array}{l}\text { Chlamydial } \\
\text { infection alone } \\
(n=153)\end{array}$} & \multicolumn{2}{|c|}{$\begin{array}{l}\text { Gonorrhoea } \\
\text { alone } \\
(n=258) \\
\end{array}$} & \multicolumn{2}{|c|}{$\begin{array}{l}N V D \\
(n=133)\end{array}$} \\
\hline & No. & $\%$ & No. & $\%$ & No. & $\%$ \\
\hline $\begin{array}{l}\text { Vaginal discharge } \\
\text { Dysuria } \\
\text { Pruritus } \\
\text { Abdominal pain } \\
\text { Frequency } \\
\text { Other } \\
\text { No symptoms }\end{array}$ & $\begin{array}{l}68 \\
13 \\
22 \\
10 \\
17 \\
13 \\
60\end{array}$ & $\begin{array}{r}44 \cdot 4 \\
8 \cdot 5 \\
14 \cdot 4 \\
6 \cdot 5 \\
11 \cdot 1 \\
8 \cdot 4 \\
39 \cdot 2\end{array}$ & $\begin{array}{r}103 \\
30 \\
16 \\
18 \\
6 \\
22 \\
124\end{array}$ & $\begin{array}{r}40 \\
12 \\
6 \\
7 \\
2 \\
9 \\
48\end{array}$ & $\begin{array}{l}44 \\
11 \\
17 \\
13 \\
11 \\
11 \\
51\end{array}$ & $\begin{array}{r}33 \\
8 \cdot 3 \\
12 \cdot 8 \\
9 \cdot 8 \\
8 \cdot 3 \\
8 \cdot 3 \\
38 \cdot 3\end{array}$ \\
\hline
\end{tabular}

Table 2 Reasons for attendance in 567 chlamydiaepositive female patients

\begin{tabular}{lrr}
\hline Reason & No. & $\%$ \\
\hline Contact of NSU & 178 & $31 \cdot 4$ \\
Contact of gonorrhoea & 122 & $21 \cdot 5$ \\
Own accord & 159 & $28 \cdot 1$ \\
General practitioner referral & 58 & $10 \cdot 2$ \\
Boyfriend (with possible STD) & 45 & $7 \cdot 9$ \\
Other & 5 & 0.9 \\
\hline
\end{tabular}

Furthermore, $122(21 \cdot 5 \%)$ patients were contacts of gonorrhoea. Possibly most of these cases would not have received treatment for their chlamydial infection without a chlamydial service. It is not standard practice for many clinics to issue contact slips to men developing post-gonococcal urethritis (PGU) and thus the treatment of the female contact for post-gonococcal non-specific genital infection (NSGI) is often overlooked-even if she has attended for follow up. Additionally, should a male patient default before PGU can be diagnosed, there is no way of excluding, or treating, NSGI in his partner even on epidemiological grounds.

Over $28 \%$ (159) of patients with chlamydial infection came to the clinic of their own accord and 58 were referred by their general practitioners, family planning clinics, or other hospital departments. A further $8 \%$ attended because they suspected that their partner had a sexually transmitted disease but were unable to provide any definite information.

Thus, $68.6 \%$ of chlamydiae-positive female patients were not contacts of NSU. In 1976, 5747 new female patients attended this department and if a conservative chlamydial isolation rate of $20 \%$ is taken it would be expected that 1149 positive isolations would be obtained. Only 361 patients (the contacts of NSU) would have been treated epidemiologically, leaving $788(68 \cdot 8 \%)$ women who were chlamydiae-positive but would not have been treated. If these results are extrapolated for the whole of England, it can be estimated that in 1976 there were 18300 women seen in clinics with undiagnosed, and, therefore, untreated, chlamydial infection. Presumably most of these patients were told that they were free from infection.

\section{CHLAMYDIAL SERVICE FOR MEN}

As chlamydiae-positive and chlamydiae-negative urethritis are treated identically in most centres, and since there have been few reports of $C$. trachomatis isolation from the male urethra in the absence of urethritis (Holmes et al., 1975; Alani et al., 1977), at first sight there would seem to be no great advantage in taking routine chlamydial cultures from all male patients.

In two areas, however, chlamydial isolation would be valuable. The first is in cases where double infection with gonococci and chlamydiae have occurred. Traditionally the after-effects of gonococcal urethritis must be eradicated before PGU can be diagnosed. This takes up to two weeks in most centres. If a chlamydial infection could be diagnosed within two or three days of the patient's first attendance treatment could be started earlier, thus reducing the time during which the patient would be under observation-a mutual benefit to patient and 
clinic staff. Secondly, it is unlikely that the vexed problems in the diagnosis and management of recurrent nongonococcal urethritis, whether it is due to relapse or reinfection, will be resolved without at least those cases due to chlamydial infection being identified.

\section{Conclusion}

A large reservoir of untreated chlamydial infection seems to exist in female patients attending similar departments in the UK. Routine screening tests or clinical findings are unlikely to be of help in such cases (Oriel et al., 1978).

Included among these patients are contacts of gonorrhoea (21.5\% in our series), and it has been suggested (Richmond and Oriel, 1978) that all women with gonorrhoea should be given antichlamydial treatment since chlamydial isolation rates among such women have been shown to be as high as 30-60\% (Hilton et al., 1974; Oriel et al., 1974; Burns et al., 1975; Woolfit and Watt, 1977).

Had we adopted such a policy in this department we would have treated $52.9 \%$ of chlamydiae-positive women (including those who were contacts of NSU) but also many gonorrhoea-positive but chlamydiaenegative women.

Encouraging reports of specific tests to detect antichlamydial antibody in both serum and local secretions have been published recently (Treharne $e t$ al., 1977, 1978) but it remains to be seen how specifically such tests reflect current as opposed to past chlamydial infection.

We believe, however, that a chlamydial diagnostic service-either by direct culture of the organism or by other means-should now be regarded as a necessity rather than a luxury.

This study was supported by a generous grant from the Research Endowments Fund, St Thomas's Hospital.
References

Alani, M. D., Darougar, S., Burns, M. D. C., Thin, R. N., and Dunn, $H$. (1977). Isolation of Chlamydia trachomatis from the male urethra. British Journal of Venereal Diseases, 53, 88-92.

Barlow, D., Nayyar, K., Phillips, I., and Barrow, J. (1976). Diagnosis of gonorrhoea in women. British Journal of Venereal Diseases, 52, 326-328.

Barlow, D. and Phillips, I. (1978). Gonorrhoea in women: diagnostic, clinical and laboratory aspects. Lancet, 1, 761-764.

Beem, M. O., and Saxon, E. M. (1977). Respiratory tract colonisation and a distinctive pneumonia syndrome in infants infected with Chlamydia trachomatis. New England Journal of Medicine, 296, 306-310.

Burns, M. D. C., Darougar, S., Thin, R. N., Lothian, L., and Nicol, C. S. (1975). Isolation of chlamydia from women attending a clinic for sexually transmitted diseases. British Journal of Venereal Diseases, 51, 314-318.

Department of Health and Social Security (1976). On the State of the Public Health. Report of the Chief Medical Officer for 1975, p. 47-51. HMSO: London.

Hilton, A. L., Richmond, S. J., Milne, J. D., Hindley, F., and Clarke, S. K. R. (1974). Chlamydia $A$ in the female genital tract. British Journal of Venereal Diseases, 50, 1-10.

Holmes, K. K. Handsfield, H. H., Wang, S. P., Wentworth, B. B., Turck, M., Anderson, J. B., and Alexander, E. R. (1975). Etiology of non-gonococcal urethritis. New England Journal of Medicine, 292, 1199-2005.

Mårdh, P.-A., Ripa, T., Svensson, L., and Westrom, L. (1977). Chlamydia trachomatis infection in patients with acute salpingitis. New England Journal of Medicine, 296, 1377-1379.

Nayyar, K. C., O'Neill, J. J., Hambling, M. H., and Waugh, M. A. (1976). Isolation of Chlamydia trachomatis from women attending a clinic for sexually transmitted diseases. British Journal of Venereal Diseases, 52, 396-398.

Oriel, J. D., Powis, P. A., Reeve, P., Miller, A., and Nicol, C. S. (1974). Chlamydial infections of the cervix. British Journal of Venereal Diseases, 50, 11-16.

Oriel, J. D., Johnson, A. L., Barlow, D., Thomas, B. J., Nayyar, K. C., and Reeve, P. (1978). Infection of the uterine cervix with Chlamydia trachomatis. Journal of Infectious Diseases, 137, 443-451.

Rees, E., Tait, A., Hobson, D., Byng, R. E., and Johnson, F. W. A. (1977). Neonatal conjunctivitis caused by Neisseria gonorrhoeae and Chlamydia trachomatis. British Journal of Venereal Diseases, 53, 173-179.

Reeve, P., Owen, J., and Oriel, J. D. (1975). Laboratory procedures for the isolation of Chlamydia trachomatis from the human genital tract. Journal of Clinical Pathology, 28, 910-914.

Richmond, S. J. and Oriel, J. D. (1978). Recognition and management of genital chlamydial infection. British Medical Journal, 2, 480-483.

Treharne, J. D., Darougar, S., and Jones, B. R. (1977). Modification of the micro-immunofluorescence test to provide a routine sero-diagnostic test for chlamydial infection. Journal of Clinical Pathology, 30, 510-517.

Treharne, J. D., Darougar, S., Simmons, P. D. and Thin, R. N. (1978). Rapid diagnosis of chlamydial infection of the cervix British Journal of Venereal Diseases, 54, 403-408.

Woolfit, J. M. G. and Watt, L. (1977). Chlamydial infection of the urogenital tract in promiscuous and non-promiscuous women. British Journal of Venereal Diseases, 53, 93-95. 